\title{
Neighborhood safety and physical inactivity in adults from Curitiba, Brazil
}

\author{
Cassiano Ricardo Rech ${ }^{1,4^{*}}$, Rodrigo Siqueira Reis ${ }^{1,2}$, Adriano Akira Ferreira Hino ${ }^{1,2}$, Ciro Romélio Rodriguez-Añez ${ }^{1,3}$, \\ Rogério Cesar Fermino ${ }^{1,2}$, Priscila Bezerra Gonçalves ${ }^{1,2}$ and Pedro Curi Hallal ${ }^{5}$
}

\begin{abstract}
Background: Neighborhood safety is one of the environmental aspects that can influence physical activity. We analyzed the association between perceived neighborhood safety and physical inactivity (PI) in adults and examined effect modification according to sociodemographic variables.

Methods: A cross-sectional study was conducted with 1,261 adults (62\% women), age 18-69 years from Curitiba, Brazil.

Results: The perception of unsafe neighborhood was higher among women, older participants, those classified in the high socioeconomic (SES) group, overweighed and also among those reporting to have PA equipments and children. The association between perception safety of walking during the day and walking for leisure (women $\mathrm{PR}=1.12 \mathrm{Cl}_{95 \%}=1.02-1.22$; men $\mathrm{PR}=0.82 \mathrm{Cl}_{95 \%}=0.64-1.05$; interaction term $\left.\mathrm{PR}=1.38 \mathrm{Cl}_{95 \%}=1.03-1.83\right)$ and safe perception was associated with $\mathrm{PI}$, just in the highest SES group ( $\mathrm{PR}=1.09 ; \mathrm{Cl}_{95 \%}=1.00-1.19 ; \mathrm{p}$ trend $=0.032$ ) when compared with their counterparts (low SES PR $=0.99 ; \mathrm{Cl}_{95 \%}=0.90-1.04 ; \mathrm{p}$ trend $=0.785$; interaction term $\mathrm{PR}=1.09$; $\mathrm{Cl}_{95 \%}=1.03-1.15 ; \mathrm{p}$ trend $=0.007$ ).
\end{abstract}

Conclusion: The perception of safety in the neighborhood was associated with PI in transport, but this association varies across of sociodemographic variables.

Keyword: Safety, Physical activity, Adults, Environment

\section{Introduction}

Physical inactivity (PI) is the $4^{\text {th }}$ leading risk factor for chronic diseases and premature mortality [1]. Inactive individuals have a higher incidence of death from cancer, heart disease and stroke [1]. In Brazil, approximately $15 \%$ of adults are physically inactive, and only $31 \%$ meet the minimum recommendations for global physical activity [2]. There is consensus that it is necessary to promote strategies to encourage individuals to become more active [3] because regular physical activity (PA), even at moderate levels, such as brisk walking for 30 minutes five or more days a week, can reduce the risk of mortality and morbidity [4]. Reducing physical inactivity can also promote better health in adults [5].

\footnotetext{
* Correspondence: crrech@hotmail.com

${ }^{1}$ Pontifícia Universidade Católica do Paraná, School of Health and

Biosciences, Physical Activity and Quality of Life Research Group (GPAQ) Curitiba, Brazil

${ }^{4}$ State University of Ponta Grossa, Ponta Grossa, Brazil

Full list of author information is available at the end of the article
}

Characteristics of the physical and social environment may contribute to physically inactive behavior [6]. Individuals living in areas with limited access to places for PA, poor lighting, poor quality sidewalks and places with social disorder (e.g., the presence of drugs, crime and robberies) are less active [7]. The association between perceived neighborhood safety and inactivity has been investigated in different countries [8,9], but the results of these studies are inconsistent and have not shown sufficient evidence of an association. Studies conducted in Brazil have also shown inconsistent results $[10,11]$. Amorim et al. [10] reported a positive association between perceived neighborhood safety and PA during leisure time, but no association with walking for transportation purposes among adults living in southern Brazil.

This inconsistency in findings is due, in part, to different safety indicators used in previous studies and to the fact that most studies have not verified the effect modification of socio-demographic variables, such as gender,

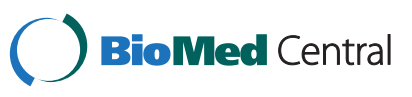


age and income. Some investigations have reported that women and elderly and low-income individuals are more likely to perceive low levels of safety in neighborhoods, which can influence their PA [7]. We hypothesize that individuals with lower perceptions of neighborhood safety (e.g., women and the elderly) are more likely to be inactive. For example, the presence of home equipment is positively associated with PA [12]. We hypothesized that people who perceive their neighborhood as less safe invest in equipment for PA practices at home (e.g., treadmills and stationary bikes). Thus, an analysis stratified by gender, income and other demographic or behavioral variables may contribute to the understanding of the relationship between perceived neighborhood safety and physical inactivity.

In Brazil, safety from crime is a serious issue. It is estimated that approximately $77 \%$ of adults are afraid of being robbed or murdered, and $75 \%$ do not trust the public safety system (e.g., police, police agencies) [13]. An analysis of the impact of environmental characteristics on levels of PA conducted in 11 countries showed that perceptions of crime and a lack of security in walking at night were higher in Brazil (65.5\%) and Colombia (74.8\%) compared with the United States (31.5\%) and Canada (16.1\%) [14]. Hence, studies on the association between PI and perceptions of neighborhood safety may contribute to design strategies for interventions in environments with higher social vulnerability.

The primary aim of this study was to determine the association between perceived neighborhood safety and physical inactivity in a sample of adults from Curitiba, Brazil. Our secondary aim was to test the effect modification of gender, income, PA equipment at home and the use of private transport.

\section{Methods}

This primary aim of this cross-sectional study was to verify the association between the utilization of public open spaces and quality of life among Brazilian adults [15]. Curitiba is a state capital in southern Brazil with a population of $1,746,896$ inhabitants ( $52 \%$ women) and is the $8^{\text {th }}$ largest city in the country. The city is recognized for its health promotion policies and special attention to green spaces as a means of sustainable development. To date, Curitiba has 19 parks $\left(18,707,232 \mathrm{~m}^{2}\right), 34$ preservation areas $\left(19,378,285 \mathrm{~m}^{2}\right)$ and 447 plazas $\left(2,750,740 \mathrm{~m}^{2}\right)$ dispersed among 75 neighborhoods [16].

Despite the high quantity of parks and plazas, some places are not intended for physical activity. Locations were selected according to their potential for PA practices and were located in neighborhoods with different economic and environmental conditions so that participants would be representative of the adult population of the city. To select the study locations (parks and plazas), in the first phase, all 75 neighborhoods of the city were classified into nine strata based on a built and social environment (ENV) index for PA and income levels. The built environment information included park density $\left(\mathrm{km}^{2} /\right.$ inhabitants), plaza density $\left(\mathrm{km}^{2} /\right.$ inhabitants $)$, bike lane density $\left(\mathrm{km}^{2} /\right.$ inhabitants), and sports and leisure department units (units/inhabitants). Crime rate (crimes/ inhabitants) and traffic accident (deaths/inhabitants) data were used as social environmental indicators. Socioeconomic status (SES) was determined based on median family income [17].

Tertiles for each score (built and social environment and income) were produced and compared in a matrix allowing the neighborhoods to be classified into nine different strata (high, medium and low environments related to PA practice and high, medium and low SES) [17]. Neighborhoods located in the four extreme clusters (high ENV and high income; high ENV and low income; low ENV and high income; and low ENV and low income) were screened to identify eight public open spaces for leisure (4 parks and 4 plazas) [18]. More details on this selection process are available elsewhere [19].

A 500-meter buffer was defined around each of the eight public locations, and all streets within this buffer were audited $(n=1,899)$. Twenty-nine percent of the street segments were not residential and were excluded from the study $(\mathrm{n}=361)$. One residence was randomly selected in each of the 1,538 eligible segments to establish geographic representation.

Participants were adults ( $\geq 18$ yrs) who had lived in the neighborhood for at least one year. Participants were randomly selected from all eligible residents within each selected household [20]. Three attempts were made on different days and times to contact subjects. Individuals who did not live in the household (e.g., maids and visitors) or those with severe physical impairments that limited PA practice or with cognitive limitations for understanding the questions were excluded.

The interviews were conducted in $95 \%$ of the eligible segments $(n=1,461)$. The refusal rate was $7.9 \%(n=121)$. Eight trained interviewers, all females with high school degrees, conducted the interviews following a 30-hour training. Quality control of the data collection was performed by field supervisors who re-interviewed 74 subjects $(12.5 \%$ of the sample). The study was approved by the Internal Review Board at the Federal University of Pelotas, and the data collection was conducted between April and July 2009.

The information on perceptions of neighborhood safety in was based on three questions derived from the Neighborhood Environmental Walkability Scale (NEWS) [21], translated into Portuguese [22] and adapted for use in Brazil. $[10,23,24]$ The following questions were used: Are there many crimes in your neighborhood?; Is it safe 
to walk during the day in your neighborhood?; and Is it safe to walk during the night in your neighborhood? The responses were dichotomized to increase clarity and understanding, and adequate test-retest reliability was obtained (overall agreement $\geq 84 \%$ and kappa $\geq 0.46$; $p<0.001$ ). A score was computed by summing the three questions to provide a global measure of neighborhood safety perception. The score ranged from 0 to 3 , with "zero" indicating a very safe neighborhood and " 3 " indicating a very unsafe neighborhood.

The long version of the International Physical Activity Questionnaire (IPAQ) [25], translated and validated for use in Brazil [26], was used to measure PA. Only the leisure and transportation modules were used in this study. Subjects reported their weekly frequency and time spent walking, performing moderate and vigorous intensity PA (MVPA) for leisure and walking for transportation in a typical week [17]. PI was defined as performing "zero" $\mathrm{min} / \mathrm{wk}$ for each category of PA (walking and MVPA for leisure and walking for transportation).

Age was grouped into five categories $(18-29,30-39$, $40-49,50-59$ and $\geq 60$ yrs). Body mass index (BMI) was computed based on self-reported information on body mass and height and was categorized into two categories (normal: BMI $\leq 24.9 \mathrm{~km} / \mathrm{m}^{2}$ and overweight: $\mathrm{BMI} \geq 25 \mathrm{~kg} / \mathrm{m}^{2}$ ). Individual SES ("high", "intermediate" and "low") was based on the number of assets within the household (e.g., television, washing machine) and educational level. Marital status was grouped into two categories ("single, separated or widower" and "married or living with someone"). Progeny was classified into two categories (having and not having). The use and frequency of private transportation was classified into three categories ("zero d/wk", "1-5 d/wk" and "6-7 d/wk"). The presence of equipment for PA practice at home [27] was classified into two categories $(0$ and $\geq 1)$.

The analytic sample size included 1,262 subjects. Bivariate associations between demographics, nutritional status and home equipment for PA and safety perception variables were tested through the chi-square test for heterogeneity and linear trend. Poisson regressions were used to verify the unadjusted association between demographics, weight status, home equipment for PA, and safety perception variables with PI. The variables significantly associated with PI in the unadjusted analysis were inserted into a multivariate model. The questions related to neighborhood safety perceptions were inserted separately into the model.

Interaction terms were created to identify the effect modification of gender and SES on safety perception variables (crimes in the neighborhood; safe to walk during the day; safe to walk during the night and score for safety perception) on PA (walking and MVPA on leisure and walking for transport). An interaction between home equipment and safety perception was created to test the effect modification of leisure PA (walking and MVPA) and private transport and safety perception variables on walking for transport. A total of 36 interactions were created. Analyses were conducted using STATA 9.2. All analyses used the sampling design through the "svy" commands, considering the 500-meter area around each park/plaza as the primary sampling unit.

\section{Results}

Approximately $62 \%$ of the participants were female (Table 1). More than half of the participants reported crimes in the neighborhood. Less than two out of ten

Table 1 Sample characteristics

\begin{tabular}{|c|c|c|c|}
\hline Variable & Categories & $\mathbf{n}$ & $\%$ \\
\hline \multirow[t]{2}{*}{ Sex } & Men & 481 & 38.1 \\
\hline & Women & 781 & 61.9 \\
\hline \multirow[t]{5}{*}{ Age group (ages) } & $18-29$ & 280 & 22.2 \\
\hline & $30-39$ & 244 & 19.3 \\
\hline & $40-49$ & 287 & 22.7 \\
\hline & $50-59$ & 293 & 23.2 \\
\hline & $\geq 60$ & 158 & 12.5 \\
\hline \multirow[t]{2}{*}{ Weight status } & Normal & 649 & 51.4 \\
\hline & Overweight & 613 & 48.6 \\
\hline \multirow[t]{3}{*}{ Socioeconomic status } & High & 153 & 12.1 \\
\hline & Medium & 631 & 50.0 \\
\hline & Low & 478 & 37.9 \\
\hline \multirow[t]{2}{*}{ Marital status } & Single & 536 & 42.5 \\
\hline & Married & 726 & 57.5 \\
\hline \multirow[t]{2}{*}{ Children } & No & 351 & 27.8 \\
\hline & Yes & 911 & 72.2 \\
\hline \multirow[t]{3}{*}{ Private transport use } & None & 335 & 26.5 \\
\hline & 1 to 5 days/week & 483 & 38.3 \\
\hline & 6 to 7 days/week & 444 & 35.2 \\
\hline \multirow[t]{2}{*}{ Home facilities for PA } & None & 736 & 58.3 \\
\hline & $\geq 1$ & 526 & 41.7 \\
\hline \multirow[t]{3}{*}{ Unsafe perception } & Crimes & 637 & 50.5 \\
\hline & Walking during the day & 201 & 15.9 \\
\hline & Walking during the night & 979 & 77.6 \\
\hline \multirow[t]{4}{*}{ Safe perception score } & 0 (more safe) & 212 & 16.8 \\
\hline & 1 & 439 & 34.8 \\
\hline & 2 & 455 & 36.1 \\
\hline & 3 (less safe) & 156 & 12.4 \\
\hline \multirow[t]{3}{*}{ Physical Inactivity } & Walking for leisure & 774 & 61.3 \\
\hline & MVPA for leisure & 871 & 69.0 \\
\hline & Walking for commuting & 376 & 29.8 \\
\hline
\end{tabular}

Curitiba, Brazil $(n=1,262)$.

PA: physical activity. MVPA: moderate and vigorous PA. 
participants considered it unsafe to walk during the day, whereas almost $80 \%$ reported that it was unsafe to walk at night. Almost two-thirds of participants were classified as inactive for leisure time, but only one-third were classified as inactive for walking as a means of transportation.

Table 2 shows that perceptions of neighborhood safety were lower among women and elderly participants, those in the high SES group, those who were overweight, those who reported having PA equipment at home, and those with children.

Individuals who perceived that it was unsafe to walk at night in the neighborhood were $27 \%$ less likely to be inactive in walking for transportation when compared with their counterparts. There were no other associations between PI and perceived neighborhood safety after adjusting for potential confounders (Table 3).

There was an effect modification of gender on the association between safety perceptions of walking during the day and walking for leisure (women $P R=1.12$, $\mathrm{CI}_{95 \%}=1.02-1.22 ;$ men $\mathrm{PR}=0.82, \quad \mathrm{CI}_{95 \%}=0.64-1.05$; interaction $\left.=1.38, \mathrm{CI}_{95 \%}=1.03-1.83\right)$ after adjusting for potential confounders.

Lower perceptions of safety were associated with inactivity in the highest SES group ( $\mathrm{PR}=1.09 ; \mathrm{CI}_{95 \%}=1.00-1.19 ; \mathrm{p}$ for trend $=0.032$ ) when compared with their lowest counterparts (low SES PR $=0.99 ; \mathrm{CI}_{95 \%}=0.90-1.04 ; \mathrm{p}$

Table 2 Association between safe perception in the neighborhood and sociodemographic variables

\begin{tabular}{|c|c|c|c|c|c|c|c|c|c|}
\hline \multirow{3}{*}{ Variables } & \multicolumn{9}{|c|}{ Unsafe perception in the neighborhood } \\
\hline & \multicolumn{3}{|c|}{ Crimes } & \multicolumn{3}{|c|}{ Walking during the day } & \multicolumn{3}{|c|}{ Walking during the night } \\
\hline & $\bar{n}$ & $\%$ & $p$ & $\bar{n}$ & $\%$ & $p$ & $\bar{n}$ & $\%$ & $p$ \\
\hline \multicolumn{10}{|l|}{ Sex } \\
\hline Men & 243 & 50.3 & 0.661 & 59 & 12.2 & 0.005 & 347 & 71.8 & $<0.001$ \\
\hline Women & 383 & 49.0 & & 142 & 18.2 & & 633 & 81.0 & \\
\hline \multicolumn{10}{|l|}{ Age group (ages) } \\
\hline $18-29$ & 118 & 42.1 & 0.08 & 32 & 11.4 & 0.001 & 206 & 73.6 & 0.001 \\
\hline $30-39$ & 137 & 56.1 & & 26 & 10.7 & & 175 & 71.7 & \\
\hline $40-49$ & 139 & 48.3 & & 50 & 17.4 & & 228 & 79.2 & \\
\hline $50-59$ & 147 & 50.2 & & 66 & 22.5 & & 239 & 81.6 & \\
\hline$\geq 60$ & 85 & 53.5 & & 27 & 17.0 & & 132 & 83.0 & \\
\hline \multicolumn{10}{|l|}{ Marital status } \\
\hline Single & 258 & 48.0 & 0.366 & 89 & 16.6 & 0.575 & 405 & 75.4 & 0.122 \\
\hline Married & 368 & 50.6 & & 112 & 15.4 & & 575 & 79.1 & \\
\hline \multicolumn{10}{|l|}{ Weight status } \\
\hline Underweight/Normal & 322 & 49.6 & 0.948 & 89 & 13.7 & 0.029 & 502 & 77.3 & 0.874 \\
\hline Overweight/Obesity & 304 & 49.4 & & 112 & 18.2 & & 478 & 77.7 & \\
\hline \multicolumn{10}{|l|}{ Socioeconomic status } \\
\hline Low & 231 & 48.3 & 0.049 & 76 & 15.9 & & 376 & 78.7 & 0.462 \\
\hline Medium & 304 & 48.2 & & 106 & 16.8 & & 490 & 77.7 & \\
\hline High & 90 & 58.8 & & 19 & 12.4 & 0.414 & 113 & 73.9 & \\
\hline \multicolumn{10}{|l|}{ Children } \\
\hline Yes & 172 & 49.0 & 0.818 & 49 & 14.0 & 0.242 & 255 & 72.6 & 0.010 \\
\hline No & 454 & 49.7 & & 152 & 16.6 & & 725 & 79.4 & \\
\hline \multicolumn{10}{|l|}{ Private transport use } \\
\hline None & 158 & 47.2 & 0.060 & 54 & 16.1 & 0.164 & 271 & 80.9 & 0.226 \\
\hline 1 to 5 days/week & 227 & 47.0 & & 87 & 18.0 & & 368 & 76.2 & \\
\hline 6 to 7 days/week & 241 & 54.0 & & 60 & 13.5 & & 341 & 76.5 & \\
\hline \multicolumn{10}{|l|}{ Home facilities to PA } \\
\hline None & 357 & 48.4 & 0.361 & 106 & 14.4 & 0.081 & 588 & 79.8 & 0.023 \\
\hline$\geq 1$ & 269 & 51.0 & & 95 & 18.0 & & 392 & 74.4 & \\
\hline
\end{tabular}


Table 3 Adjusted association between physical inactivity and safety in the neighborhood in adults

\begin{tabular}{|c|c|c|c|c|c|c|c|c|c|c|}
\hline \multirow[t]{3}{*}{ Variable } & \multirow[t]{3}{*}{ Category } & \multicolumn{9}{|c|}{ Physical inactivity } \\
\hline & & \multicolumn{3}{|c|}{ Walking for leisure $^{a}$} & \multicolumn{3}{|c|}{ MVPA $^{\mathrm{b}}$} & \multicolumn{3}{|c|}{ Walking for commuting $^{c}$} \\
\hline & & $\%$ & PR (C195\%) & $\mathrm{p}$ & $\%$ & PR (Cl95\%) & $p$ & $\%$ & PR (Cl95\%) & $\mathrm{p}$ \\
\hline \multicolumn{11}{|c|}{ Safety from crime } \\
\hline & Safe & 60.5 & 1.00 & & 71.3 & 1.00 & & 30.3 & 1.00 & \\
\hline & Unsafe & 62.2 & $0.99(0.94-1.06)$ & 0.858 & 66.7 & $1.05(0.98-1.13)$ & 0.104 & 29.3 & $1.11(0.77-1.60)$ & 0.506 \\
\hline \multicolumn{11}{|c|}{ Is safe walk during the day } \\
\hline & Safe & 61.2 & 1.00 & & 68.5 & 1.00 & & 30.2 & 1.00 & \\
\hline & Unsafe & 62.2 & $1.03(0.95-1.11)$ & 0.363 & 71.6 & $0.99(0.90-1.09)$ & 0.821 & 27.9 & $0.96(0.69-1.34)$ & 0.387 \\
\hline \multicolumn{11}{|c|}{ Is safe walk during at night } \\
\hline & Safe & 62.3 & 1.00 & & 62.9 & 1.00 & & 38.2 & 1.00 & \\
\hline & Unsafe & 61.1 & $0.97(0.82-1.15)$ & 0.741 & 70.8 & $1.04(0.90-1.22)$ & 0.463 & 27.4 & $0.73(0.57-0.94)$ & 0.023 \\
\hline \multicolumn{11}{|c|}{ Scale of neighborhood safety } \\
\hline & 0 (more safe) & 69.2 & 1.00 & $0.905^{*}$ & 73.8 & 1.00 & $0.271^{*}$ & 58.5 & 1.00 & $0.491^{*}$ \\
\hline & 1 & 60.4 & $1.05(0.84-1.30)$ & 0.610 & 66.7 & $1.14(0.93-1.40)$ & 0.171 & 28.5 & $0.98(0.61-1.57)$ & 0.929 \\
\hline & 2 & 61.9 & $0.97(0.81-1.17)$ & 0.734 & 71.1 & $1.12(0.91-1.36)$ & 0.228 & 28.1 & $0.87(0.52-1.44)$ & 0.525 \\
\hline & 3 (less safe) & 56.4 & $1.06(0.94-1.19)$ & 0.275 & 69.2 & $1.11(0.89-1.37)$ & 0.271 & 25.6 & $0.94(0.58-1.52)$ & 0.766 \\
\hline
\end{tabular}

Curitiba, Brazil $(n=1,262)$.

PA: physical activity.

MVPA: moderate and vigorous PA.

${ }^{a}$ Adjusted for sex, age, SES, private transport use and home facilities to PA.

${ }^{\mathrm{b}}$ Adjusted for sex, age, nutritional status, SES, marital status, children, private transport use and home facilities to PA.

${ }^{\mathrm{c} A d j u s t e d}$ for sex, age, SES, marital status, private transport use.

*p trend.

for trend $=0.785$; interaction term $\mathrm{PR}=1.09 ; \mathrm{CI}_{95 \%}=1.03-1.15$; $\mathrm{p}$ for trend $=0.007$ ).

The relationship between perceptions of safety and PI for MVPA showed an effect modification by home equipment for PA. There was a trend toward increased PI for moderate-vigorous activities higher perceptions of a lack of safety $\left(\mathrm{PR}=1.05 ; \mathrm{CI}_{95 \%}=1.00-1.11\right.$; $\mathrm{p}$ trend $\left.=0.04\right)$, but only for participants who reported not having facilities for $\mathrm{PA}$ at home (interaction term $\mathrm{PR}=0.93 \mathrm{CI}_{95 \%}=0.85-1.01$; $p=0.07)$.

We observed that a higher perception of a lack of safety for walking at night was associated with a lower risk of inactivity in walking for transportation for all categories of private transport use (6-7 days/wk $\mathrm{PR}=0.75$, $\mathrm{IC}_{95 \%}=0.60-0.94 ; 5-6$ days $/$ wk $\mathrm{PR}=0.84 \quad \mathrm{IC}_{95 \%}=0.62-$ 1.12 ; none $\left.\mathrm{PR}=0.46 \mathrm{CI}_{95 \%}=0.29-0.71\right)$. However, this relationship differed significantly between those reporting 6-7 days/week (interaction term $\mathrm{PR}=1.62, \mathrm{CI}_{95 \%}=1.11-$ 2.36, $p=0.021$ ) and $1-5$ days $/$ wk (interaction term $\mathrm{PR}=1.91$; $\left.\mathrm{CI}_{95 \%}=1.50-2.44 ; p=0.001\right)$ compared with those who did not use private transport.

\section{Discussion}

The aim of this study was to examine the relationship between perceived neighborhood safety and PI according to specific domains and types of activities (walking and performing MVPA for leisure and walking for transportation).
The results indicated that associations were domainspecific and varied according to the safety indicator. We also observed that this association was modified by gender, age and SES. It is believed that certain groups are more vulnerable to perceptions of a lack of safety in the neighborhood, which may undermine the relationship with PA [7]. The results of this study support evidence that women and elderly and high SES individuals have lower perceptions of neighborhood safety [7,28].

The relationship between PI and perceptions of safety was found to be complex in this study. After adjusting for confounders, only individuals who perceived that it was unsafe to walk at night in the neighborhood were less likely to be inactive in transport. Similar results were found in studies conducted in Brazil $[11,23,29]$. The inverse relationship found in this study may be explained by two main reasons. First, individuals who walk more may see more crimes while commuting and therefore may have lower perceptions of safety when compared with individuals who spend more time at home or who walk less. Second, walking for transportation is a utilitarian activity, and some people need to walk even though they perceive the neighborhood as unsafe. This situation results in higher exposure to an unsafe environment. In fact, we found that approximately $80 \%$ of individuals perceived their surroundings as unsafe when walking at night. This relationship was modified by the use of 
private transport (cars). Individuals who regularly used a car (6 to 7 days/week) and considered their neighborhood unsafe were less likely to be inactive.

Multivariate analysis showed no association between the perception of neighborhood safety and PI in leisure time. However, when analyzing the association according to gender, we found that women with higher perceptions of a lack of safety were more likely to be inactive in walking during leisure time than men. This effect modification of gender was observed in other studies that demonstrated a consistent association among women $[7,30]$. In part, these results may be explained by other psychosocial mediators. For instance, greater perceived self-efficacy among men may increase perceptions of neighborhood safety because evidence suggests an interaction between these factors [31]. Because physical inactivity is usually higher among women, increasing perceptions of neighborhood safety in could be a useful strategy to prevent PI in this group. Evidence indicates that improvements in lighting and aesthetics can contribute to decreasing feelings of a lack of safety and perceptions of crime in neighborhoods [32]. This is an important fact for public health promotion, particularly in Brazil and other areas with a high prevalence of crime. For instance, in Brazil, women lose an average of 43.3 years of life due to homicides [33], which contributes to other social and economic problems in society.

The modified effect of SES on the association between perceived safety and PI has been investigated in different populations $[34,35]$. We found that individuals with high SES and increased perceptions of insecurity were more likely to be inactive than those with medium or low SES. In general, low-SES individuals are more vulnerable to unsafe neighborhoods [35], but this does not necessarily indicate greater perceptions of a lack of safety because individuals incorporates this insecurity into their daily lives. Thus, it can be inferred that high-SES individuals may report more insecurity, a feeling that may be shared by other members of the group. In this context, social norms may play an important role in neighborhood perceptions of safety.

Finally, these results demonstrate that the relationship between perceived neighborhood safety and PI is complex, and the effect modification of demographic characteristics (e.g., gender, SES) may explain this association. Interventions to increase perceived neighborhood safety are priorities in specific population groups (women, elderly individuals and individuals with high SES). Insecurity is a major barrier to active behavior, yet little is known about the mechanisms of this relationship [7]. We suggest that future studies should examine the indirect effect of perceived neighborhood safety on PI through intrapersonal (self-efficacy, enjoyment) and interpersonal (social support) variables [6].
Some limitations and strengths should be considered for better interpretation and extrapolation of these results. Although the sample is not representative of Curitiba, the sample size is sufficient to detect associations [33]. The sampling design was considered, but this characteristic was not controlled in the analyses. The cross-sectional design does not allow us to draw causal relationships. The measurements of safety and PI were obtained by self-reported measures, so errors in judgment or misinterpretation are expected. Despite these limitations, these measures are commonly used in PA studies and have shown good reliability and reasonable validity. Finally, a strength of this study is the overall process, which included household surveys.

\section{Conclusion}

Physical inactivity in the form of walking for transportation was lower among individuals with high perceptions of unsafe neighborhoods, and this association was stronger among individuals who regularly used private transportation. Other results suggest that women and individuals with high SES are less active in walking for leisure when they perceive a neighborhood as unsafe. It is suggested that further studies should test the effect modification of socio-demographic variables in this relationship and should analyze the indirect effects on perceptions of neighborhood safety of interpersonal and intrapersonal aspects related to PI.

\section{Competing interests}

The authors declare that they have no competing of interests.

\section{Authors' contributions}

RCR, FRC, GPB, HAAF, and conceived designed the study, prepared the data, conducted the analysis and interpretation of data. RACR, RRS, contributed to study design, data interpretation, and writing. HPC, contributed to study design and revised the manuscript for important intellectual content. All authors read and approved the final.

\section{Author details}

PPontifícia Universidade Católica do Paraná, School of Health and Biosciences, Physical Activity and Quality of Life Research Group (GPAQ), Curitiba, Brazil. ${ }^{2}$ Federal University of Parana, Curitiba, Brazil. ${ }^{3}$ Federal Technological University of Parana, Curitiba, Brazil. ${ }^{4}$ State University of Ponta Grossa, Ponta Grossa, Brazil. ${ }^{5}$ Federal University of Pelotas, Pelotas, Brazil.

Received: 3 December 2011 Accepted: 30 May 2012

Published: 12 June 2012

\section{References}

1. Woodcock J, Franco OH, Orsini N, Roberts I: Non-vigorous physical activity and all-cause mortality: systematic review and meta-analysis of cohort studies. Int J Epidemiol 2011, 40:121-138.

2. Brasil: Telephone-based Surveillance of Risk and Protective Factors for Chronic Diseases (VIGITEL). Brasilia: Ministério da Saúde; 2010.

3. People $\mathrm{H}$, Health USDo, Services $\mathrm{H}$, International Medical Publishing I: Healthy people 2010. US: Dept. of Health and Human Services; 2000.

4. Haskell WL, Lee I: Physical activity and public health. Updated recommendation for adults from the American College of Sports Medicine and the American Heart Association. Circulation 2007, 116:1081-1093. 
5. Blair SN: Physical inactivity: the biggest public health problem of the $21 \mathrm{st}$ century. British Journal of Sports Medicine 2009, 43:1-2.

6. McNeill LH, Wyrwich KW, Brownson RC, Clark EM, Kreuter MW: Individual, social environmental, and physical environmental influences on physical activity among black and white adults: a structural equation analysis. Ann Behav Med 2006, 31:36-44.

7. Foster S, Giles-Corti B: The built environment, neighborhood crime and constrained physical activity: an exploration of inconsistent findings. Prev Med 2008, 47:241-251.

8. McGinn AP, Evenson KR, Herring AH, Huston SL, Rodriguez DA: The association of perceived and objectively measured crime with physical activity: a cross-sectional analysis. J Phys Act Health 2008, 5:117-131.

9. Gomez JE, Johnson BA, Selva M, Sallis JF: Violent crime and outdoor physical activity among inner-city youth. Prev Med 2004, 39:876-881.

10. Amorim TC, Hallal PC, Azevedo MR Jr: Physical activity levels according to physical and social environmental factors in a sample of adults living in south Brazil. J Phys Act Health 2010, 7:S204-S212.

11. Parra DC, Hoehner CM, Hallal PC, Ribeiro IC, Reis RS, Brownson RC, Pratt M, Simoes EJ: Perceived environmental correlates of physical activity for leisure and transportation in Curitiba, Brazil. Preventive medicine 2011, 52:234-238.

12. Trost SG, Owen N, Bauman AE, Sallis JF, Brown W: Correlates of adults' participation in physical activity: review and update. Medicine \& Science in Sports \& Exercise 1996, 2002:34.

13. IPEA: Sistema de indicadores de percepção social: segurança pública. In Book Sistema de indicadores de percepção social: segurança pública. 2011 [http://www.ipea.gov.br/portal/images/stories/PDFs/SIPS/110207_sipssaude. pdf]

14. Sallis JF, Bowles HR, Bauman A, Ainsworth BE, Bull FC, Craig CL, Sjostrom M, De Bourdeaudhuij I, Lefevre J, Matsudo V, et al: Neighborhood environments and physical activity among adults in 11 countries. Am J Prev Med 2009, 36:484-490.

15. Pucci G, Reis RS, Rech CR, Hallal PC: Quality of life and physical activity among adults: population-based study in Brazilian adults. Qual Life Res 2012. doi:10.1007/s11136-0083-5.

16. IPPUC: Urban Research and Planning Institute of Curitiba. Curitiba data. 2009: 2009; 2009. Available from: [http://ippucweb.ippuc.org.br/Bancodedados/ Curitibaemdados/Curitiba_em dados_Pesquisa.htm]

17. Reis RS, Hallal PC, Parra DC, Ribeiro IC, Brownson RC, Pratt M, Hoehner CM, Ramos L: Promoting physical activity through community-wide policies and planning: findings from Curitiba, Brazil. J Phys Act Health 2010, 7:S137-S145.

18. Hino AAF, Reis RS, Parra D, Ribeiro IC, Brownson RC, Fermino RC: Using observational methods to evaluate public open spaces and physical activity in Brazil. J Phys Act Health 2010, 7:S146-S154.

19. Pucci GCMF, Rech CR, Fermino RC, Reis RS: Association between physical activity and quality of life in adults. Revista de Saúde Pública 2012, 46:166-179

20. Kish L: Sampling organizations and groups of unequal sizes. American sociological review 1965, 30:564-572.

21. Saelens BE, Sallis JF, Black JB, Chen D: Neighborhood-Based Differences in Physical Activity: An Environment Scale Evaluation. Am J Public Health 2003, 93:1552-1558.

22. Malavasi LM, Duarte MFS, Both J, Reis RS: Neighborhood walkability scale (News - Brazil): Back translation and Reliability. Revista Brasileira de Cineantropometria e Desempenho Humano 2007, 9:339-350.

23. Florindo AA, Salvador EP, Reis RS, Guimarães W: Perception of the environment and practice of physical activity by adults in a low socioeconomic area. Revista de Saúde Pública 2011, 45:302-310.

24. Salvador EP, Reis RS, Florindo AA: Practice of walking and its association with perceived environment among elderly Brazilians living in a region of low socioeconomic level. Int J Bev Nutrit Phys Activity 2010, 7:2-7.

25. Craig CL, Marshall AL, Sjöström M, Bauman AE, Booth ML, Ainsworth BE, Pratt $M$, Ekelund U, Yngve A, Sallis JF, Oja P: International physical activity questionnaire: 12-country reliability and validity. Med Sci Sports Exerc 2003, 35:1381-1395

26. Matsudo SMM, Araújo T, Matsudo VKR, Andrade D, Andrade E, Oliveira LC, Braggion G: International physical activity questionnaire (IPAQ): study of validity and reability in Brazil. Rev Bras Ativ Fís Saúde 2001, 6:5-18.

27. Gonçalves PB, Reis RS, Rodriguez Añez CR, Florindo AA: Validity and reliability of a questionnaire to evaluate physical activity related to home environment in older women. Revista Brasileira de Atividade Física e Saúde 2010, 15:82-87.

28. Giles-Corti B, Donovan RJ: The relative influence of individual, social and physical environment determinants of physical activity. Soc Sci Med 2002 54:1793-1812

29. Salvador EP, Reis RS, Florindo AA: Practice of walking as a means of locomotion and its association with the perception of the environment in the elderly. Revista Brasileira de Atividade Física e Saúde 2009, 14:197-205.

30. Suminski RR, Poston WSC, Petosa RL, Stevens E, Katzenmoyer LM: Features of the neighborhood environment and walking by US adults. Am J Prev Med 2005, 28:149-155.

31. Mariëlle B, Carlijn K, Alex B, Johan M: Sports participation, perceived neighborhood safety, and individual cognitions: how do they interact? International Journal of Behavioral Nutrition and Physical Activity 2011, 8:1-8.

32. Painter $\mathrm{K}$ : The influence of street lighting improvements on crime, fear and pedestrian street use, after dark. Landscape and Urban Planning 1996, 35:193-201.

33. Silva LS, Menezes MLN, Lopes CLA, Corrêa MSM: Years of potential life lost by female homicide victims in Recife, Pernambuco State, Brazil. Cad Saúde Pública 2011, 27:1721-1730.

34. Wilson DK, Kirtland KA, Ainsworth BE, Addy CL: Socioeconomic status and perceptions of access and safety for physical activity. Ann Behav Med 2004, 28:20-28.

35. Brownson RC, Baker EA, Housemann RA, Brennan LK, Bacak SJ: Environmental and policy determinants of physical activity in the United States. Am J Public Health 1995, 2001:91.

doi:10.1186/1479-5868-9-72

Cite this article as: Rech et al:: Neighborhood safety and physical inactivity in adults from Curitiba, Brazil. International Journal of Behavioral Nutrition and Physical Activity 2012 9:72.

\section{Submit your next manuscript to BioMed Central and take full advantage of:}

- Convenient online submission

- Thorough peer review

- No space constraints or color figure charges

- Immediate publication on acceptance

- Inclusion in PubMed, CAS, Scopus and Google Scholar

- Research which is freely available for redistribution 